\title{
Diversity in fragments of artificial and natural marine habitats
}

\author{
Paris J. Goodsell* \\ Centre for Research on Ecological Impacts of Coastal Cities, Marine Ecology Laboratories, A11, University of Sydney, \\ New South Wales 2006, Australia
}

\begin{abstract}
In fragmented landscapes the matrix, i.e. the surrounding but different habitat, can have a strong influence on the biodiversity in fragments. The amount of natural habitat converted for urban use is increasing on every continent, so fragments of natural habitat are becoming more likely to be embedded in a matrix of human-made habitat, rather than other natural habitats. This is particularly prevalent on urbanised coastlines. Yet there has been little research to help us understand the dynamics and consequences of fragmented coastal landscapes. In Sydney, Australia, most of the natural intertidal landscape of Sydney Harbour (a mosaic of rocky shore, mudflats and sandflats) has been replaced by artificial habitat (such as seawalls). I tested the hypothesis that biota on rocky shores in Sydney Harbour would differ depending on whether shores were embedded in a matrix of artificial habitat (here called 'complete fragments'), natural habitat (here called 'natural patches'), or a mixture of the 2 types of matrix (called mixed fragments). Assemblages at mid-shore levels were significantly different among these types of fragments. At mid- and low-shore levels, assemblages were more variable in mixed fragments than in complete fragments and natural patches. The kinds of mobile and sessile taxa that contributed most to differences among fragments differed, depending on which types of fragments were compared. Many taxa were found in greater abundance in natural patches than in mixed or complete fragments, although not all comparisons were statistically significant. Artificial habitat seems to interrupt natural connectivity among local populations of intertidal marine organisms in this urbanised estuary.
\end{abstract}

KEY WORDS: Matrix $\cdot$ Conservation $\cdot$ Habitat structure $\cdot$ Intertidal $\cdot$ Rocky shore $\cdot$ Intertidal organisms Resale or republication not permitted without written consent of the publisher

\section{INTRODUCTION}

Fragmentation can create mosaics of different habitats from once homogenous landscapes, or can modify the composition and arrangement of different patches within a naturally patchy landscape. Each of these actions has the potential to alter functional connectivity within a landscape, i.e. the transfer of resources and individuals, with the associated consequences for biodiversity (Dunning et al. 1992). Individuals must travel or disperse over larger distances across relatively hostile matrix (Tischendorf \& Fahrig 2000), often leading to reduced local turnover and increased risk of (local) extinction (Brown \& Kodric-Brown 1977). The extent to which connectivity is reduced in fragmented landscapes can, however, be strongly affected by charac- teristics of the matrix (Ricketts 2001, Vandermeer \& Carvajal 2001). Rarely is the matrix a complete barrier to dispersal (Taylor et al. 1993). Rather, the extent to which dispersal is altered is a combination of the structure of the matrix and the behavioural and physiological responses of the biota.

The amount of natural habitat converted for urban use is increasing globally (United Nations 2004). Fragments of natural habitat are hence becoming more likely to be embedded in a matrix of human-made habitat, rather than other natural habitats, which may be a significant barrier to the movement and dispersal of individuals (Forman \& Alexander 1998). One of the fundamentals of landscape ecology is to understand linkages between different components of habitat, including anthropogenic elements (Forman 1995). Water, like air, presum- 
ably enables greater connectivity across heterogeneous landscapes than across land; hence, studies in 'waterscapes' provide good opportunities to understand dynamics within fragmented habitats (Wiens 2002). Further, because many major cities (e.g. New York, Hong Kong), are built on waterways, such as estuaries and rivers, their shorelines are subject to substantial fragmentation and urbanisation. Little is understood of the potential consequences of this fragmentation for biota in these linear, coastal landscapes. Whilst it is often assumed that marine organisms are not affected by fragmentation, because they have dispersive planktonic larvae, many experience direct development or the planktonic phase is short-lived (Roberts \& Hawkins 1999), or behavioural and physical processes lead to local retention of larvae (Cowen et al. 2000). There is increasing evidence that marine biota are, indeed, affected by isolation of habitat and changes in the suitability of matrix habitat (e.g. Goodsell \& Connell 2002, Roberts \& Poore 2006, Tanner 2006).

In Sydney, Australia, $>50 \%$ of the intertidal landscape of Sydney Harbour has been replaced by artificial habitats, such as seawalls (Chapman 2003). Many rocky shores exist as fragments (patches) bounded on both sides by artificial habitat (here called 'complete fragments'). There are also patches surrounded by natural habitat (here called 'natural patches'), which have not been created by human disturbance, and some patches in intermediate condition, which are bordered at one end by natural habitat and by artificial habitat at the other (here called 'mixed fragments'). The term 'fragment' is used to describe rocky shores that are more likely to be patches due to some human disturbance (i.e. are adjacent to at least one artificial surface) rather than patches that exist naturally (Goodsell et al. 2007).

Artificial habitats may simply provide extra habitat for organisms that rely on hard surfaces and do not, therefore, affect connectivity among rocky shores (Thompson et al. 2002). There is convincing evidence, however, that seawalls contain different and fewer taxa (Chapman 2003, Bulleri \& Chapman 2004, Bulleri et al. 2005), and there are differences in the size, fecundity (Moreira et al. 2006) and behaviour (Bulleri et al. 2004) of organisms on seawalls compared to those on rocky shores. Moreover, complete fragments in Sydney Harbour are smaller and further away from each other than are natural patches (Goodsell et al. 2007). Changes to the configuration and composition of coastal landscapes caused by replacing natural with artificial habitat may have predictable ecological consequences for biota on rocky shores that have been fragmented. Based on currently accepted theory (e.g. Tischendorf et al. 2005) dispersal or movement across the landscape may be different where patches are further apart and now separated by a matrix of artificial habitat (i.e. seawalls) rather than natural habitat.
Before experiments can be done to determine the patterns of movement of organisms across modified landscapes (true connectivity), it must be established that assemblages are indeed different in urban versus natural landscapes (e.g. Underwood et al. 2000, Li \& Wu 2004). In the current study, I predicted that biota on rocky shores in Sydney Harbour would differ depending on whether shores were embedded in a matrix of artificial habitat (complete fragments), natural habitat (natural patches), or a mixture of the 2 types of matrix. Shores bordered on one side by artificial structures and on the other by natural habitat were called 'mixed fragments'. Mobile taxa or those with large dispersal capabilities have a better ability to move among fragmented landscapes (Hansson 1991, With et al. 1997). Whilst many marine organisms can disperse via the water column, only mobile taxa can move across habitats after recruitment. I, therefore, predicted that assemblages of sessile organisms would be distributed differently from those of mobile taxa among different types of fragments (natural patches vs. complete and mixed fragments). Seawalls are a more homogenous habitat than are natural rocky shores (Chapman 2003), and the matrix is known to exert a stronger influence on biota in fragments (Ricketts 2001). I, therefore, also predicted that the structure of assemblages would be more variable within and among replicate shores of natural patches than among mixed or complete fragments.

\section{MATERIALS AND METHODS}

Three replicate shores of each type of fragment (natural patches, mixed and complete fragments) were sampled. These were chosen from suitable shores in the harbour to be of similar length (mean $\pm \mathrm{SE}=98.6 \pm$ $12.6 \mathrm{~m}$ ), where the length of the matrix was longer than the shore ( $>150 \mathrm{~m}$ ) and was of entirely artificial or entirely natural habitat, between adjacent shores. The substratum of all shores was sandstone with a gentle slope. Shores were exposed to moderate swell and occasional wash from boat traffic.

Biota on replicate shores were sampled over approximately 2 mo in September and October of austral summer, 2004. Height on the shore affects the structure of intertidal assemblages, so 2 assemblages were sampled on each shore. Mid- and low-shore assemblages vary from shore to shore in the range of heights they occupy. Sampling was therefore not done according to height on the shore, rather mid-shore assemblages were identified by the presence of the oyster Saccostrea commercialis and/or barnacles. The ascidian Pyura stolonifera and/or the tube-building polychaete Galeolaria caespitosa characterised low-shore assemblages (e.g. Chapman 2003). 
Two sites $(5 \times 5 \mathrm{~m})$, separated by at least $5 \mathrm{~m}$, were sampled on each shore at each of the mid- and lowshore levels. In each site, the relative abundance and composition of taxa were sampled using 5 haphazardly placed quadrats $(25 \mathrm{~cm} \times 20 \mathrm{~cm})$. Percent coverage of sessile organisms (algae and invertebrates) and of bare space was estimated from 100 points in a grid across the quadrat; mobile organisms were identified and counted (e.g. Underwood \& Chapman 1996, Chapman \& Bulleri 2003).

All shores were interspersed within Sydney Harbour to reduce the likelihood that patterns in the data were simply due to the position of shores in the harbour (Fig. 1). I tested the hypotheses that there were no relationships between the spatial arrangement of the fragments and the structure of assemblages, by correlating differences in the biological data (abundance of mobile animals and percent coverage of sessile organisms) with (1) distances in a straight line between each shore and (2) distances of each shore from a point midway between North and South Head at the mouth of the harbour (Fig. 1) using RELATE (PRIMER: Clarke \& Warwick 1994). I found that the biological data were not correlated with the distances of each site from the midway point at the mouth of the harbour - neither for the mid-shore $(\rho=-0.20 ; p>0.80)$ nor for the low-shore levels $(\rho=0.19 ; p>0.20)$. Nor were they significantly correlated with the distances between all sites for midshore $(\rho=0.32 ; p>0.10)$ or for low-shore levels $(\rho=$ $0.35 ; \mathrm{p}>0.10$ ).

Differences in the structure of assemblages (untransformed data were the abundance of mobile animals and the percent coverage of sessile animals) among the different types of fragment at the 2 spatial scales (among sites on shores and among shores) were tested using a 3-factor, nested PERMANOVA (formerly NPMANOVA; Anderson 2001, 2005). This analysis partitions the variability in multivariate dissimilarity measures, producing a pseudo F-ratio with a permuted null distribution (4999 permutations). Bray-Curtis measures of dissimilarity calculated on raw data (Bray \& Curtis 1957) were used because these are considered best to illustrate patterns in data that have many zeroes and are over-dispersed (Clarke et al. 2006). Fourth-root transformation is often used to overcome dominance of abundant taxa in multivariate analysis. In the current study, when fourth-root transformed data were analysed, results were similar to those when untransformed data were analysed, so results from the latter are presented. Separate analyses were done for mid- and low-shore assemblages because these were selected, a priori, to differ from each other.

\section{RESULTS}

A total of 72 taxa were found from 12 phyla and $>48$ families, including gastropods, mussels, oysters, tube worms, sea-stars, anemones and encrusting and branching algae.

Mid-shore assemblages were significantly different among the different types of fragments (Table 1, Fig. 2a). Post hoc multivariate comparisons, however, could not detect which types of fragments actually

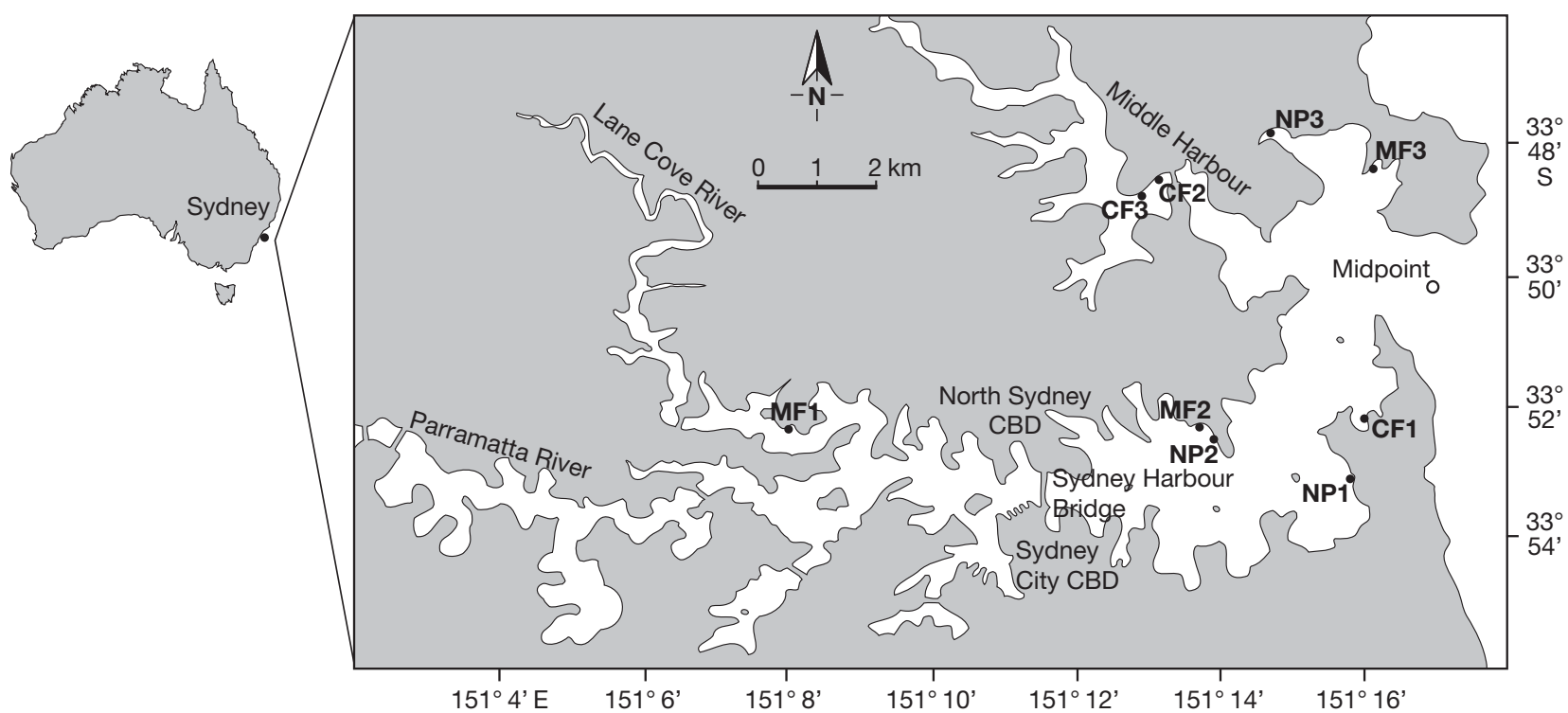

Fig. 1. Location of study sites in Sydney Harbour, Australia. Three replicate sandstone shores of each fragment type were sampled NP: shore with natural habitat on both sides (natural patches); MF: shores with an artificial habitat (seawall) on one side and a natural habitat on the other (mixed fragments); CF: shores with an artificial matrix on both sides (complete fragments). Linear distances of fragments from each other and from a midway point at the mouth of the harbour (O) were measured. CBD: Central Business District 
Table 1. Results of PERMANOVA; multivariate analyses of Bray-Curtis dissimilarities among assemblages in different fragments: mid-shore and low-shore levels. Two randomly chosen 'sites' $\left(5 \mathrm{~m}^{2}\right)$ were nested within 3 randomly chosen 'shores' of different 'fragments' (fixed factor: natural patches vs. mixed fragments vs. complete fragments; see 'Introduction'). The average Bray-Curtis dissimilarities within (top diagonal line of values in measures of dissimilarity) and between (italics) different fragments are given

\begin{tabular}{|c|c|c|c|c|}
\hline Source & df & MS & $F$ & $\mathrm{p}$ \\
\hline \multicolumn{5}{|l|}{ Mid-shore } \\
\hline Fragment & 2 & 18586.4 & 1.8 & $<0.05$ \\
\hline Shore (Fragment) & 6 & 10440.3 & 3.8 & $<0.001$ \\
\hline Site (Shore [Fragment]) & 9 & 2757.5 & 1.5 & $<0.05$ \\
\hline Residual & 72 & 1872.4 & & \\
\hline \multicolumn{5}{|l|}{ Low-shore } \\
\hline Fragment & 2 & 815.8 & 1.2 & $>0.20$ \\
\hline Shore (Fragment) & 6 & 9980.7 & 2.3 & $<0.001$ \\
\hline Site (Shore[Fragment]) & 9 & 4307.2 & 1.7 & $<0.05$ \\
\hline Residual & 72 & 2522.3 & & \\
\hline \multicolumn{5}{|c|}{$\begin{array}{l}\text { Average measures of dissimilarity between and within } \\
\text { (among shores) different fragments }\end{array}$} \\
\hline & & Natural & Mixed & Complete \\
\hline \multicolumn{5}{|l|}{ Mid-shore } \\
\hline Natural & & 31 & & \\
\hline Mixed & & 50 & 61 & \\
\hline Complete & & 39 & 56 & 38 \\
\hline \multicolumn{5}{|l|}{ Low-shore } \\
\hline Natural & & 33 & & \\
\hline Mixed & & 39 & 49 & \\
\hline Complete & & 46 & 50 & 48 \\
\hline
\end{tabular}

differed, because the possible number of permutations (10) was not sufficient to do a reasonable test with a significance level of 0.05 . Nonetheless, average measures of dissimilarity show that mid-shore assemblages in natural patches were more different from those in mixed than from those in complete fragments (average dissimilarity of 50 vs. $39 \%$; Table 1). Assemblages in mixed fragments were more different from those in complete fragments than from those in natural patches (Table 1). Whilst there was some overlap, assemblages in natural patches plotted somewhat separately from those in complete and mixed fragments, as did assemblages in the latter 2 types of fragments (Fig. 2a).

At mid-shore levels, there was significant variability among the 3 replicate shores (separated by kilometres) for each type of fragment (Table 1). It was predicted that assemblages in natural patches and mixed fragments would be more variable among shores than would those in complete fragments. Contrary to predictions, assemblages were more similar among natural patches and complete fragments, than among mixed fragments (average dissimilarity of 31 and 38 (a) Mid-shore assemblages

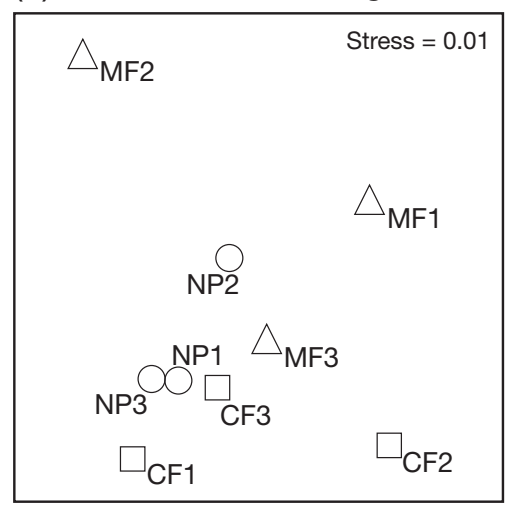

(b) Low-shore assemblages

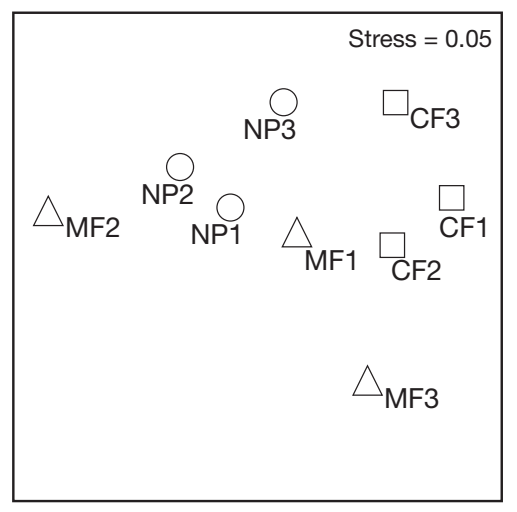

Fig. 2. nMDS plots of the centroids for replicate shores of the 3 types of fragments for (a) mid-shore and (b) low-shore assemblages. NP: natural patches $(O)$; MF: mixed fragments $(\Delta)$; CF: complete fragments $(\square)$

vs. $61 \%$; Table 1). Clear differences in the dispersion of replicate shores among the different types can also be seen in the nMDS plot (Fig. 2a). Shores of mixed fragments plotted further apart from each other than did those of complete fragments or natural patches (Fig. 2a).

Mid-shore assemblages were also significantly different between replicate sites (separated by metres) within shores of each type of fragment (Table 1). I predicted that variability between sites would be greater in natural patches and mixed fragments than in complete fragments. Bray-Curtis measures of dissimilarity were calculated between pairs of randomly chosen quadrats, 1 quadrat in each pair from each site within each shore (and fragment). These were used to give independent measures of multivariate variability between sites for each shore (Underwood \& Chapman 1998). I compared these sites among shores within different types of fragments using analysis of variance (ANOVA). Variability between sites was similar among replicate shores, but varied significantly among the different types of fragments (Table 2). Student-Newman-Keuls (SNK) tests 
Table 2. Analysis of Bray-Curtis measures of dissimilarity between sites on shores within different fragments at mid-shore and low-shore levels. Five independent measures of dissimilarity were calculated from pairs of quadrats between the 2 sites on each 'shore' (random factor; 3 levels) within different 'fragments' (fixed factor: natural patches vs. mixed fragments vs. complete fragments; see 'Introduction')

\begin{tabular}{|lrrlc|}
\hline Source & df & MS & $F$ & $p$ \\
\hline Mid-shore & & & & \\
Fragment & 2 & 3391.4 & 6.6 & $<0.05$ \\
Shore(Fragment) & 6 & 512.8 & 0.72 & $>0.60$ \\
Residual & 36 & 714.9 & & \\
Low-shore & & & & \\
Fragment & 2 & 1406.0 & 5.5 & $<0.05$ \\
Shore(Fragment) & 6 & 256.9 & 0.5 & $>0.80$ \\
Residual & 36 & 568.8 & & \\
\hline
\end{tabular}

did not provide a logical alternative to the null hypothesis, but the greatest variability between sites occurred in mixed fragments (mean \pm SE: $74 \pm 7 \%$ ) and the least variability between sites occurred in complete fragments $(44 \pm 7 \%)$.

Many of the patterns detected in assemblages at mid-shore levels were not consistent at low-shore levels. Lowshore assemblages did not differ significantly among the different types of fragments (Table 1). The average measure of dissimilarity between natural patches and complete fragments was greater than that between natural patches and mixed fragments (Table 1). Similarly, complete fragments plotted separately from natural patches and from mixed fragments (Fig. 2b).

Similar to patterns at mid-shore levels, there was significant variability among replicate shores (separated by kilometres) within each type (Table 1), possibly reducing the detection of significant differences among types of fragments. Similar to mid-shore levels, assemblages in mixed fragments were more variable among shores (plotting further apart from each other), than were those in complete fragments and natural patches (Fig. 2b).

Low-shore assemblages were also significantly different between sites (separated by metres) within shores of each type of fragment (Table 1). ANOVA detected significant variability between sites among the different types of fragments (Table 2). SNK tests did not provide a logical alternative to the null hypothesis, but the greatest variability between sites occurred, as predicted, in natural patches (mean \pm SE: $85 \pm 3 \%$ ). Unlike mid-shore assemblages, mixed fragments had the least amount of within-shore variability (67 $\pm 7 \%$ ).

Contrary to predictions, the structure of sessile assemblages (percent coverage of algae and sessile animals) was not clearly different from that of the mobile assemblage (abundance) between sites (PERMANOVA: $\mathrm{p}<0.05$ for mobile and sessile taxa), among shores (PERMANOVA: $\mathrm{p}<0.05$ for mobile and sessile taxa), or among the different types of fragment (PERMANOVA: $\mathrm{p}>0.05$ for mobile and sessile taxa) for each of the mid- and low-shore assemblages. Moreover, patterns for mobile and sessile taxa, for the most part, reflected those of the assemblage as a whole (Fig. 3). Assemblages in natural patches plotted somewhat separately from those in complete fragments, and variability at the scale of kilometres (among shores) was greatest in mixed fragments (compare Table 1, Figs. 2 \& 3). At mid-shore levels, the mobile taxa contributing the most (>5\%) to differ-
Mobile taxa

(a) Mid-shore assemblages

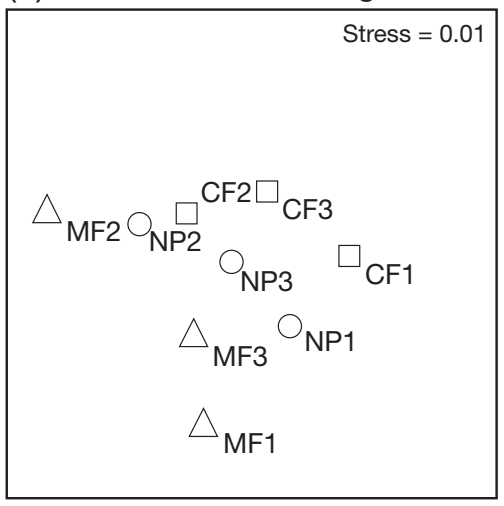

(b) Low-shore assemblages

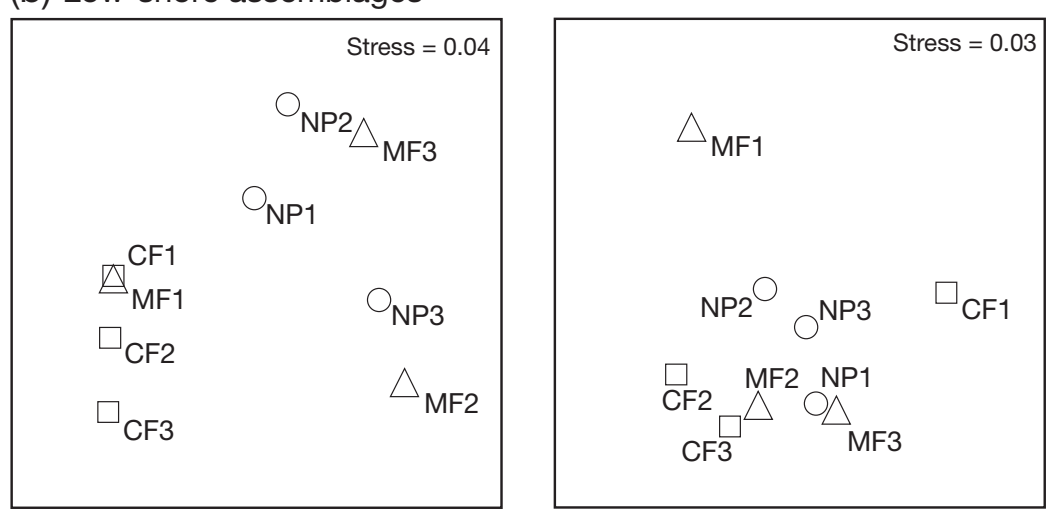

Fig. 3. nMDS plots of the centroids for replicate shores of the 3 types of fragments. NP: natural patches $(O)$; MF: mixed fragments $(\Delta)$; CF: complete fragments $(\square)$. Data are for mobile and sessile taxa for (a) mid-shore and (b) low-shore assemblages 
ences among types of fragments were snails: the littorinid Bembicium nanum and the trochid Austrocochlea porcata. The sessile taxa contributing the most were the Sydney rock oyster Saccostrea commercialis and the encrusting alga Hildenbrandia rubra (Table 3). There were differences between the mobile and sessile taxa that contributed the most to differences among the different types of fragments (Table 3). Some of these taxa were found in greater abundance in natural patches than in mixed or complete fragments, e.g. A. porcata and H. rubra (Fig. 4), although these differences were not statistically significant (ANOVA: $p>0.05$ ). Other taxa were found in significantly greater abundance in complete fragments, e.g. B. nanum (ANOVA: p < 0.05; Fig. 4).

\section{DISCUSSION}

The structure of assemblages on fragments of rocky shore differed depending on the nature of the surrounding matrix at mid-shore levels. I predicted that assemblages in complete fragments would be the most different from those in natural patches, because their matrices represent boundaries with the most and least altered habitats, respectively. Nevertheless, I found that assemblages in mixed fragments were the most different from each of the other 2, at least at mid-shore levels. The current study suggests that assemblages in naturally patchy habitats differ from those in fragmented, urban habitats. Biotas in the current study were sampled at one time, so no temporal extrapolations are possible. It is unlikely that the differences found would substantially differ through time because most of these seawalls have been in place for decades. I examined fragments of similar sizes and which were

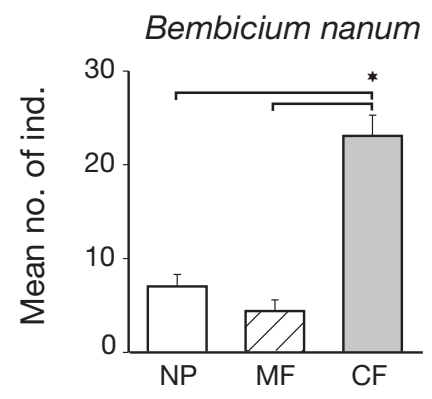

Austrocochlea porcata
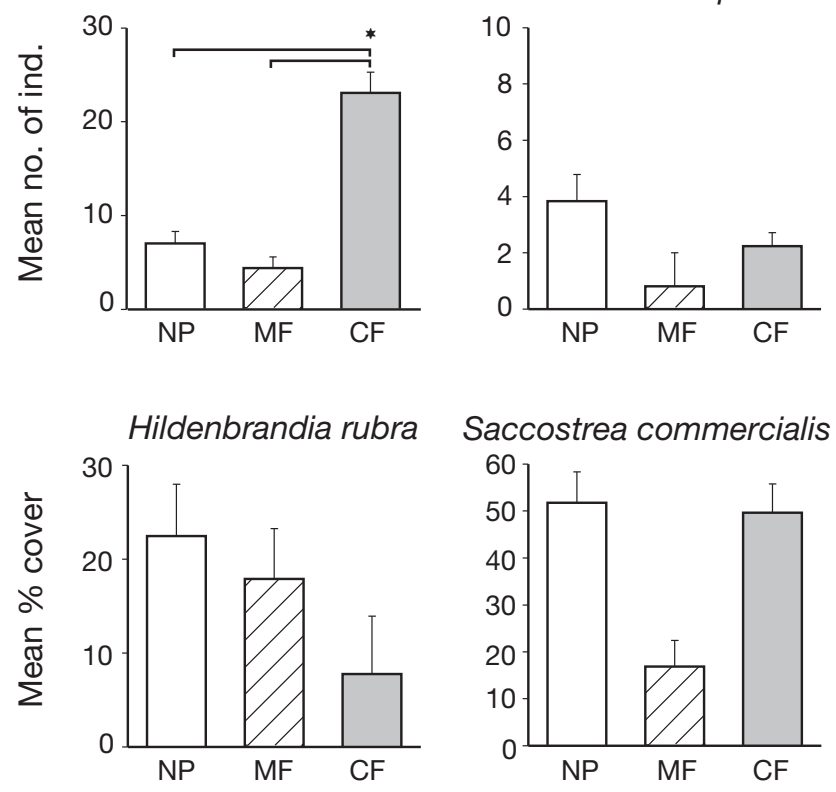

Fig. 4. Mean $( \pm \mathrm{SE})$ abundance (per fragment) of mobile and sessile taxa contributing $>5 \%$ to measures of dissimilarity among natural patches (NP), mixed fragments (MF) and complete fragments (CF) at mid-shore levels. *Significant difference among types of fragment as detected by ANOVA $(p<0.05)$

separated by similar distances to adjacent shores (i.e. the proportion of intervening matrix between the sampled patch and the next rocky shore on each side was also similar), so the observed differences are probably due to the characteristics of the matrix and cannot be confounded by size or by distance between fragments. Artificial structures are sometimes described as providing extra habitat for organisms that rely on hard substrata, i.e. those that live on rocky shores (Thomp-

Table 3. Percentage contribution of taxa $(>5 \%)$ to differences among natural patches, mixed and complete fragments (see 'Introduction') at mid-shore levels

\begin{tabular}{|lrlrl|}
\hline Natural vs. mixed & $\%$ & Natural vs. complete & $\%$ & Mixed vs. complete \\
\hline Mobile taxa & & & & \\
Bembicium nanum & 32 & Bembicium nanum & 53 & Bembicium nanum \\
Austrocochlea porcata & 16 & Austrocochlea porcata & 12 & Patelloida mimula \\
Siphonaria denticulata & 10 & Patelloida mimula & 8 & Austrocochlea porcata \\
Cellana tramoserica & 7 & Chiton pelliserpentis & 5 & \\
Siphonaria virgulata & 7 & & & \\
Chiton pelliserpentis & 5 & & & \\
Sessile taxa and bare space & & & 34 & Saccostrea commercialis \\
Saccostrea commercialis & 31 & Saccostrea commercialis & 30 \\
Hildenbrandia rubra & 19 & Hildenbrandia rubra & 21 & Ralfsia verrucosa \\
Bare space & 15 & Bare space & 16 & Hildenbrandia rubra \\
Enteromorpha sp. & 13 & Ralfsia verrucosa & 14 & Enteromorpha sp. \\
Ralfsia verrucosa & 8 & & & Bare space \\
Crassostrea gigas & 5 & & & Crassostrea gigas \\
\hline
\end{tabular}


son et al. 2002). There is, however, increasing evidence to the contrary (Chapman 2003, Chapman \& Bulleri 2003, Bulleri et al. 2005, Moreira et al. 2006). The current study specifically examined propositions about whether structures like seawalls affect assemblages on adjacent rocky shores.

Variability in natural assemblages (e.g. abundance, composition and density) is a common and important phenomenon (Landres et al. 1999). Differences in variability in the structure of assemblages from site to site (separated by metres) and from shore to shore (separated by kilometres) were obvious among the different types of fragments. Contrary to the predictions, however, natural patches had less variability at the scale of kilometres (among shores) than did complete or mixed fragments. In contrast, the numbers of taxa on rocky shores in Sydney Harbour were more variable in natural patches than in complete or mixed fragments (Goodsell et al. 2007). Interestingly, variability on a scale of metres (among sites) was smaller in complete fragments than in natural patches, at least at mid-shore levels. Anthropogenic impacts can increase (Warwick $\&$ Clarke 1993) or decrease (Chapman et al. 1995) variability in assemblages of marine organisms. Mechanisms causing differences in variability among different types of fragments can, as yet, only be suggested. It is clear though that different measures of the structure of assemblages (e.g. number of taxa vs. their relative abundance) might be affected in different ways by fragmentation. It is hence likely that there are complex and species-specific responses to fragmentation and urbanisation (Henle et al. 2004). For example, fragmentation of rocky shores may increase variability in the relative composition of assemblages (i.e. the abundances and frequencies of taxa), but decrease variability in the number of taxa.

Differences in the kinds of taxa among fragments were evident. Little is known about the dispersive capabilities of some of the taxa which contributed most to differences among types of fragments (e.g. Hildenbrandia rubra), so it is difficult to make generalisations about the characteristics of taxa that are most affected. It may be that taxa found in greater abundances in natural than in complete fragments would be those less capable of dispersing great distances because complete fragments are further apart from one another than are natural patches (e.g. Dethier et al. 2003).

Movement for some species is said to be restricted to a greater extent when boundaries are 'hard' (Dunning et al. 1992, Collinge \& Palmer 2002). That I found differences between natural and complete fragments where the boundary for each was similarly 'hard' (i.e. the fragment ends abruptly at an edge with artificial or soft-sediment habitat) suggests that the nature of the matrix itself has more influence than the boundary per se. Furthermore, fragments of rocky shore may be connected mainly via recruitment through the water column, rather than through movement across boundaries after recruitment (e.g. Bulleri 2005a,b). Similar to wind-dispersed plants or mobile mammals and insects (Soons et al. 2005), organisms that do not necessarily encounter habitat as they disperse may be affected more by particular aspects of landscape structure (e.g. the amount of suitable habitat, the distance between habitats and the type of matrix habitat). For example, complete fragments in Sydney Harbour are smaller (mean length: $156 \mathrm{~m}$ ) and further away from each other (mean distance between adjacent fragments: $631 \mathrm{~m}$ ) than are natural patches (average length: $414 \mathrm{~m}$; mean distance between patches: $378 \mathrm{~m}$; Goodsell et al. 2007). The probability of 'landing' on a suitable piece of habitat is, therefore, lower for complete fragments than for naturally patchy habitats.

The extent to which the matrix differs from that of suitable habitat in patches has strong effects on the connectivity among fragments (Johnson et al. 1992, Wiens et al. 1997). Urban matrices are often less suitable as habitat than are natural habitat and, thus, can substantially restrict the exchange or use of resources (e.g. Wegner \& Merriam 1979, Forman \& Alexander 1998). Although seawalls are hard substrata, their characteristics are very different from those of rocky shores. They have different slopes, exposure and topography and do not provide adequate habitat for the full suite of taxa found naturally on rocky shores (Chapman 2003, Chapman \& Bulleri 2003, Bulleri \& Chapman 2004, Bulleri et al. 2005). Even where the same taxa are found on artificial structures, important ecological processes, such as fecundity and behaviour, are different on artificial structures than they are on rocky shores (Bulleri et al. 2004, Moreira et al. 2006). Whilst soft sediments (i.e. the natural matrix habitats in the current study) are often very different from rocky shore habitats, natural patches are larger and closer together in Sydney Harbour than are complete fragments. So, assemblages are probably better connected on natural patches. The regional pool of taxa available to recruit to fragments with urban matrices may be smaller (because complete fragments are smaller) or recruitment is limited because urban matrices are too extensive (and not suitable as intermediate habitat) or, more likely, a combination of these factors.

Differences in assemblages among natural patches, mixed fragments and complete fragments may also be due to invasion from taxa that mostly live in the matrix (e.g. Ås 1999). Seawalls are clearly not entirely impermeable to many species, and some species exist in very large densities on seawalls (Chapman 2003). Certain taxa on seawalls may 'invade' fragments adjacent to seawalls and take up space (i.e. they may be competi- 
tively dominant or more tolerant of the harsher conditions experienced on seawalls than on rocky shores).

Further experimental research is necessary to unravel the complex dynamics that occur in fragmented and artificial landscapes. Landscapes in any system are made of networks of patches of habitat that vary in their suitability and spatial arrangement. If populations are discrete, but inter-connected by dispersal and recruitment within such landscapes (e.g. Hanski 1994), understanding the consequences of urbanising habitats is crucial to conserve biodiversity. I show clear evidence that differences in the composition and arrangement of intertidal habitats from a natural to an artificial mosaic have consequences for taxa that have previously been thought not to be susceptible to fragmentation because of large dispersive capabilities (Thompson et al. 2002). As Wiens (2002, p 512) so eloquently argued, there is much to be learned by 'taking the 'land' out of landscape ecology'.

Acknowledgements. This work was possible through financial support by the Australian Research Council's Special Research Centres Programme. I thank A. Boden, G. Cocco, A. Grigaliunas, P. Hill, C. Myers and J. Smith for their help in the field. This research benefited greatly from discussions with Professors A. J. Underwood and M. G. Chapman. Thanks to anonymous reviewers for improving the manuscript.

\section{LITERATURE CITED}

Anderson MJ (2001) Permutation test for univariate or multivariate analysis of variance and regression. Can J Fish Aquat Sci 58:626-639

Anderson MJ (2005) PERMANOVA: a FORTRAN computer program for permutational multivariate analysis of variance. Department of Statistics, University of Auckland, New Zealand

Ås S (1999) Invasion of matrix species in small habitat patches. Conserv Ecol 3:1. Available at: www.consecol.org/vol3/ iss1/art1

> Bray JR, Curtis JT (1957) An ordination of the upland forest communities of southern Wisconsin. Ecol Monogr 27:325-349

Brown JH, Kodric-Brown A (1977) Turnover rates in insular biogeography: effect of immigration on extinction. Ecology 58:445-449

Bulleri F (2005a) Experimental evaluation of early patterns of colonisation of space on rocky shores and seawalls. Mar Environ Res 60:355-374

Bulleri F (2005b) Role of recruitment in causing differences between intertidal assemblages on seawalls and rocky shores. Mar Ecol Prog Ser 287:53-65

Bulleri F, Chapman MG (2004) Intertidal assemblages on artificial and natural habitat in marinas on the north-west coast of Italy. Mar Biol 145:381-391

Bulleri F, Chapman MG, Underwood AJ (2004) Patterns of movement of the limpet Cellana tramoserica on rocky shores and retaining seawalls. Mar Ecol Prog Ser 281: 121-129

Bulleri F, Chapman MG, Underwood AJ (2005) Intertidal assemblages on seawalls and vertical rocky shores in Sydney Harbour, Australia. Austral Ecol 30:655-667
Chapman MG (2003) Paucity of mobile species on constructed seawalls: effects of urbanization on biodiversity. Mar Ecol Prog Ser 264:21-29

Chapman MG, Bulleri F (2003) Intertidal seawalls — new features of landscape in intertidal environments. Landsc Urban Plan 62:159-172

Chapman MG, Underwood AJ, Skilleter GA (1995) Variability at different spatial scales between a subtidal assemblage exposed to the discharge of sewage and two control assemblages. J Exp Mar Biol Ecol 189:103-122

Clarke KR, Warwick RM (1994) Change in marine communities: an approach to statistical analysis and interpretation. Natural Environmental Research Council, Plymouth

Clarke KR, Chapman MG, Somerfield PJ, Needham HR (2006) Dispersion-based weighting of species counts in assemblage analyses. Mar Ecol Prog Ser 320:11-27

Collinge SK, Palmer TM (2002) The influences of patch shape and boundary contrast on insect response to fragmentation in California grasslands. Landscape Ecol 17:647-656

> Cowen RK, Lwiza KMM, Sponaugle S, Paris CB, Olson DB (2000) Connectivity of marine populations: open or closed? Science 287:857-859

> Dethier MN, McDonald K, Strathman RR (2003) Colonization and connectivity of habitat patches for coastal marine species distant from source populations. Conserv Biol 17: 1024-1035

> Dunning JB, Danielson BJ, Pulliam HR (1992) Ecological processes that affect populations in complex landscapes. Oikos 65:169-175

Forman RTT (1995) Land mosaics: the ecology of landscapes and regions. Cambridge University Press, Cambridge

> Forman RTT, Alexander LE (1998) Roads and their major ecological effects. Annu Rev Ecol Syst 29:207-231

> Goodsell PJ, Connell SD (2002) Can habitat loss be treated independently of habitat configuration? Implications for rare and common taxa in fragmented landscapes. Mar Ecol Prog Ser 239:37-44

> Goodsell PJ, Chapman MG, Underwood AJ (2007) Differences between biota in anthropogenically fragmented habitats and in naturally patchy habitats. Mar Ecol Prog Ser 351:15-23

Hanski I (1994) Patch-occupancy dynamics in fragmented landscapes. Trends Ecol Evol 9:131-135

Hansson L (1991) Dispersal and connectivity in metapopulations. Biol J Linn Soc 42:89-103

Henle K, Davies KF, Kleyer M, Margules CR, Settele J (2004) Predictors of species sensitivity to fragmentation. Biodivers Conserv 13:207-251

Johnson AR, Wiens JA, Milne BT, Crist TO (1992) Animal movements and population dynamics in heterogenous landscapes. Landscape Ecol 7:63-75

Landres PA, Morgan P, Swansonc FJ (1999) Overview of the use of natural variability concepts in managing ecological systems. Ecol Appl 9:1179-1188

Li HB, Wu JG (2004) Use and misuse of landscape indices. Landscape Ecol 19:389-399

> Moreira J, Chapman MG, Underwood AJ (2006) Seawalls do not sustain viable populations of limpets. Mar Ecol Prog Ser 322:179-188

Ricketts TH (2001) The matrix matters: effective isolation in fragmented landscapes. Am Nat 158:87-99

- Roberts CM, Hawkins JP (1999) Extinction risk in the sea. Trends Ecol Evol 14:241-246

> Roberts DA, Poore AGB (2006) Habitat configuration affects colonisation of epifauna in a marine algal bed. Biol Conserv 127:18-26

Soons MB, Messelink JH, Jongejans E, Heil GW (2005) Habi- 
tat fragmentation reduces grassland connectivity for both short-distance and long-distance wind-dispersed forbs. J Ecol 93:1214-1225

Tanner JE (2006) Landscape ecology of interactions between seagrass and mobile epifauna: the matrix matters. Estuar Coast Shelf Sci 68:404-412

Taylor PD, Fahrig L, Henein K, Merriam G (1993) Connectivity is a vital element of landscape structure. Oikos 68: 571-573

Thompson RC, Crowe TP, Hawkins SJ (2002) Rocky intertidal communities: past environmental changes, present status and predictions for the next 25 years. Environ Conserv 29: 168-191

Tischendorf L, Fahrig L (2000) On the usage and measurement of landscape connectivity. Oikos 90:7-19

Tischendorf L, Grez A, Zaviezo T, Fahrig L (2005) Mechanisms affecting population density in fragmented habitat. Ecol Soc 10:7. Available at: www.ecologyandsociety.org/ vol10/iss1/art7

Underwood AJ, Chapman MG (1996) Scales of spatial patterns of distribution of intertidal invertebrates. Oecologia 107:212-224

Underwood AJ, Chapman MG (1998) Spatial analyses of intertidal assemblages on sheltered rocky shores. Aust J

Editorial responsibility: Hans Heinrich Janssen,

Oldendorf/Luhe, Germany
Ecol 23:138-157

Underwood AJ, Chapman MG, Connell SD (2000) Observations in ecology: you can't make progress on processes without understanding the patterns. J Exp Mar Biol Ecol 250:91-115

United Nations (2004) World urbanization prospects: the 2003 revision. Population Division, Department of Economic and Social Affairs, United Nations, New York

> Vandermeer J, Carvajal R (2001) Metapopulation dynamics and the quality of the matrix. Am Nat 158:211-220

> Warwick RM, Clarke KR (1993) Comparing the severity of disturbance: a meta-analysis of marine macrobenthic community data. Mar Ecol Prog Ser 92:221-231

Wegner JF, Merriam G (1979) Movements by birds and small mammals between a wood and adjoining farmland habitats. J Appl Ecol 16:349-357

Wiens JA (2002) Riverine landscapes: taking landscape ecology into the water. Freshw Biol 47:501-515

Wiens JA, Schooley RL, Weeks RD Jr (1997) Patchy landscapes and animal movements: Do beetles percolate? Oikos 78:257-264

- With KA, Gardner RH, Turner MG (1997) Landscape connectivity and population distributions in heterogeneous environments. Oikos 78:151-169

Submitted: July 8, 2008; Accepted: March 27, 2009

Proofs received from author(s): May 14, 2009 